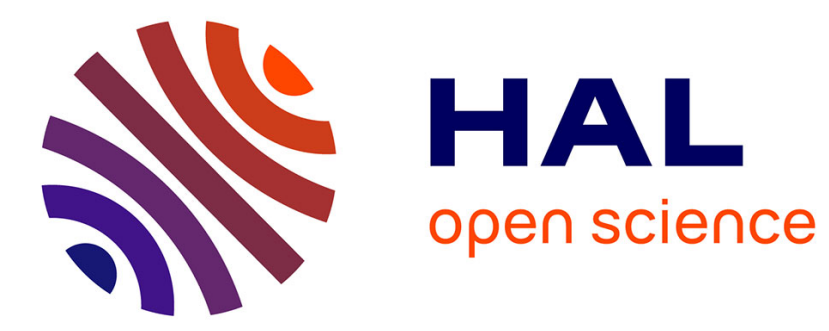

\title{
Can daylight-PDT be performed indoor?
}

Serge Mordon, A S Vignion-Dewalle, E Thecua, C Vicentini, C Maire, P.

Deleporte, G Baert, F. Lecomte, L Mortier

\section{To cite this version:}

Serge Mordon, A S Vignion-Dewalle, E Thecua, C Vicentini, C Maire, et al.. Can daylight-PDT be performed indoor?. GIORNALE ITALIANO DI DERMATOLOGIA E VENEREOLOGIA, 2018. hal-01712039

\section{HAL Id: hal-01712039 \\ https://hal.science/hal-01712039}

Submitted on 19 Feb 2018

HAL is a multi-disciplinary open access archive for the deposit and dissemination of scientific research documents, whether they are published or not. The documents may come from teaching and research institutions in France or abroad, or from public or private research centers.
L'archive ouverte pluridisciplinaire HAL, est destinée au dépôt et à la diffusion de documents scientifiques de niveau recherche, publiés ou non, émanant des établissements d'enseignement et de recherche français ou étrangers, des laboratoires publics ou privés. 


\title{
Can daylight-PDT be performed indoor?
}

S. MORDON1, A.S. VIGNION-DEWALLE1, E. THECUA 1, C. VICENTINI1,2, C. MAIRE 1,2, P. DELEPORTE1, G. BAERT 1, F. LECOMTE1, L. MORTIER ${ }^{1,2}$

IUniv. Lille, Inserm, CHU Lille, U1189 - ONCO-THAI - Image Assisted Laser Therapy for Oncology, Lille, France,

2 Department of Dermatology, CHU Lille, Lille, France

\author{
Address \\ INSERM Unité 1189 ONCO-THAI \\ 1, avenue Oscar Lambret \\ 59037 LILLE Cedex France \\ Phone: +33320446708 \\ Fax : + +33 320446738 \\ serge.mordon @inserm.fr
}

\begin{abstract}
Natural DayLight-mediated PhotoDynamic Therapy (NDL-PDT) is an efficacious treatment option for thin actinic keratosis that offers advantages over conventional PDT in terms of tolerability, treatment duration, and cost. It is now accepted that the minimum criteria required for effective NDL-PDT is a dose of $4 \mathrm{~J} / \mathrm{cm}^{2}$ with a treatment time of $2 \mathrm{~h}$ and a minimum temperature of $10^{\circ} \mathrm{C}$, corresponding to a minimum illuminance of 11000 lux. This value is easily achievable: 20000 lux can be obtained during a typical overcast day at midday. It can reach 110000 lux with a bright sunlight

However, it is limited to certain times of the year at our latitude. However rain and cold temperatures appear the main limitations of NDL-PDT. Greenhouses make possible to perform the illumination even in harsh weather conditions. Furthermore, it is difficult to install a greenhouse everywhere. Several solutions are now proposed to carry out indoor illumination so-called artificial white light or simulated daylight (SDL-PDT). Illumination sources installed at the ceiling of the treatment room is one option. Several lamp pairs can be combined to illuminate groups of patients simultaneously. A surgical theatre light can be used or dedicated systems using white LEDs can be used to deliver the required illumination dose. In conclusion, Indoor lightning (or simulated daylight: SDL-PDT or Artificial White Light: AWL) could offer an interesting alternative to NDL-PDT.
\end{abstract}

\section{Key Words}


Photodynamic Therapy, Actinic Keratosis, Light Emitting Diode, Artificial White Light 


\section{Introduction}

Natural DayLight-mediated PhotoDynamic Therapy (NDL-PDT), in which the photosensitizing agent is activated by natural light, is an increasingly popular concept that originated in Scandinavia '. All PpIX absorption peaks are within the visible spectrum of light which makes daylight a good candidate for PDT. Typically, after a patient applies a chemical sunscreen to block unwanted components of ultraviolet exposure, he or she applies methyl aminolevulinate. Within 30 minutes, patients can begin exposure to daylight, lasting for 2 hours, with light ranging from fully cloudy to a clear blue sky. It is now accepted that the minimum criteria required for effective daylight PDT is a dose of $4 \mathrm{~J} / \mathrm{cm}^{2}$ with a treatment time of $2 \mathrm{~h}$ and a minimum temperature of $10^{\circ} \mathrm{C}$, corresponding to a minimum illuminance of 11000 lux 2,3. This value is easily achievable: 20000 lux can be obtained during a typical overcast day at midday and can reach 110000 lux with a bright sunlight 4 .

This new illumination technique is starting to catch on in other European Countries 5-9, Australia 10, Central and South America 11,12 and United States 13. NDL-PDT is less expensive and far less painful than traditional conventional PDT (CPDT), in which the photosensitizer is activated by a LED panel. Another advantage of NDL-PDT is the ability to treat a larger surface area in only one session, compared to LED panel.

While it is not approved by the Food and Drug Administration for use in the United States, NDL-PDT is a registered treatment modality in Europe, Australia, and South America. NDL-PDT has been demonstrated to have high efficacy with results similar to conventional PDT for the treatment of Actinic Keratosis (AKs) ${ }^{14}$.

In fact, though there may be a sufficiently light dose in most locations, the ambient temperature may be too low, becoming a limiting factor in recommending NDL-PDT, in particular for the early months of the year 15. In fact, production of PpIX is a strongly temperature-dependent process 16 . No PplX synthesis was observed when the skin temperature was reduced to 12-18 ${ }^{\circ} \mathrm{C} 17$. Another main concern is the risk of rain which is difficult to predict when giving an appointment to the patient. Changing weather conditions with more than $30 \%$ of days with rain each month, this appears to be an insurmountable obstacle 5 .

Consequently, the treatment is very dependent on geographical location (latitude) and time of the year. Several studies have determined when NDLPDT is feasible. For example, in Denmark it is only possible to perform NDL-PDT from April to November.

Similarly, O'Mahoney et al have identified suitable months for performing NDLPDT in UK. Again, the main limitation was not light but temperature between October and March in most northern countries. Temperature data showed that it could be too cold for NDL-PDT even when there is sufficient light exposure. 
Consequently, several solutions are now proposed to carry out indoor illumination in order to mimic NDL-PDT.

\section{Greenhouse}

In rainy, cold or windy weather conditions, with sufficient natural daylight, a greenhouse can be a good solution ${ }^{18}$. Lerche et al have measured that with clear blue sky the fluence rate of daylight outside the greenhouse was 6.07 $\mathrm{mW} / \mathrm{cm}^{2}$ (PplX-weighted) corresponding to $43.7 \mathrm{~J} / \mathrm{cm}^{2}$ in two hours, while inside the greenhouse it was $4.58 \mathrm{~mW} / \mathrm{cm}^{2}$ (PplX-weighted) corresponding to $32.9 \mathrm{~J} / \mathrm{cm}^{2}$ in two hours. Thus there was a difference of $1.5 \mathrm{~mW} / \mathrm{cm}^{2}$, caused by the filter effect of the greenhouse glass. In overcast conditions the fluence rate of PplX-weighted daylight was $1.69 \mathrm{~mW} / \mathrm{cm}^{2}$ outside the greenhouse corresponding to $12.1 \mathrm{~J} / \mathrm{cm}^{2}$ in two hours and $1.18 \mathrm{~mW} / \mathrm{cm} 2$ inside the greenhouse corresponding to $8.5 \mathrm{~J} / \mathrm{cm}^{2}$ in two hours resulting in a difference of $0.5 \mathrm{~mW} / \mathrm{cm}^{2}$. The spectrum of daylight inside the greenhouse is slightly affected by the glass used for the greenhouse

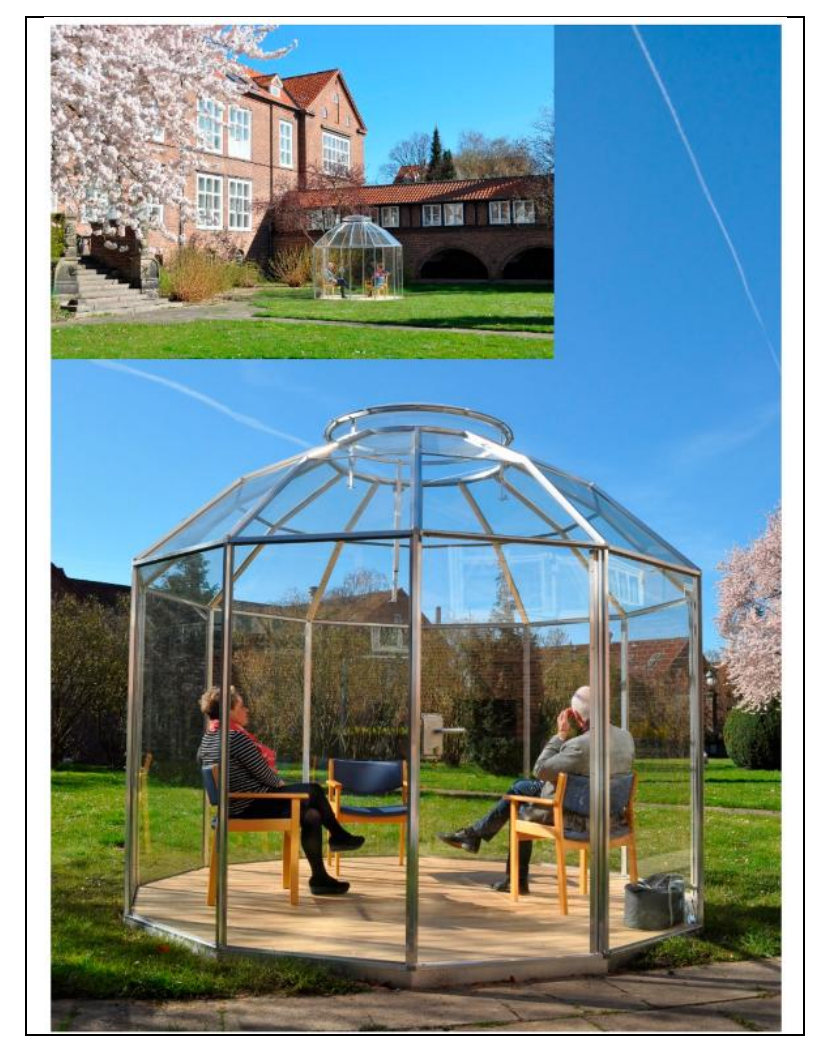

Figure 1: Greenhouse used in Denmark for NDL-PDT. This greenhouse is composed with one layer window glass with acrylic at the very top (from Lerche et al). 
However, only a limited number of Dermatologists has access to a garden or a park to install a greenhouse.

\section{Artificial white light or simulated daylight}

Due to the limitations of NDL-PDT, several teams are now considering using artificial "daylight", also called Indoor lightning, artificial white light or simulated daylight (SDL-PDT) to treat patients all year round.

Lerche et al have evaluated five different artificial Daylight sources 18. They found that four of the five light sources were usable for SDL-PDT. In the following, only commercially available systems, specifically developed for PDT of AKs will be described.

\section{Surgical theater light source}

O'Gorman et al have proposed to use an operating room light source because it had a suitable spectrum, output, distribution of the light emitting diodes (LEDS) 19. They evaluated a device commercially available (Maquet Power LED - MPLED500). The illuminance of this theatre light is similar to that on a clear summer's day. The manufacturer's spectrum shows a broad waveband in the visible range with high amplitude at $630 \mathrm{~nm} 20$.

Figure 2 shows the spectrum of this artificial light source (White LED). A white LED is composed of a blue chip with a phosphor coating. The coating converts blues into a chemically-controlled spectrum of photons across the entire visible spectrum. "Warm white" LEDs have a short $460 \mathrm{~nm}$ blue peak and a broad slope from green to red. "Cool white" LEDs have a tall $460 \mathrm{~nm}$ blue peak and a very similar slope from green to red.

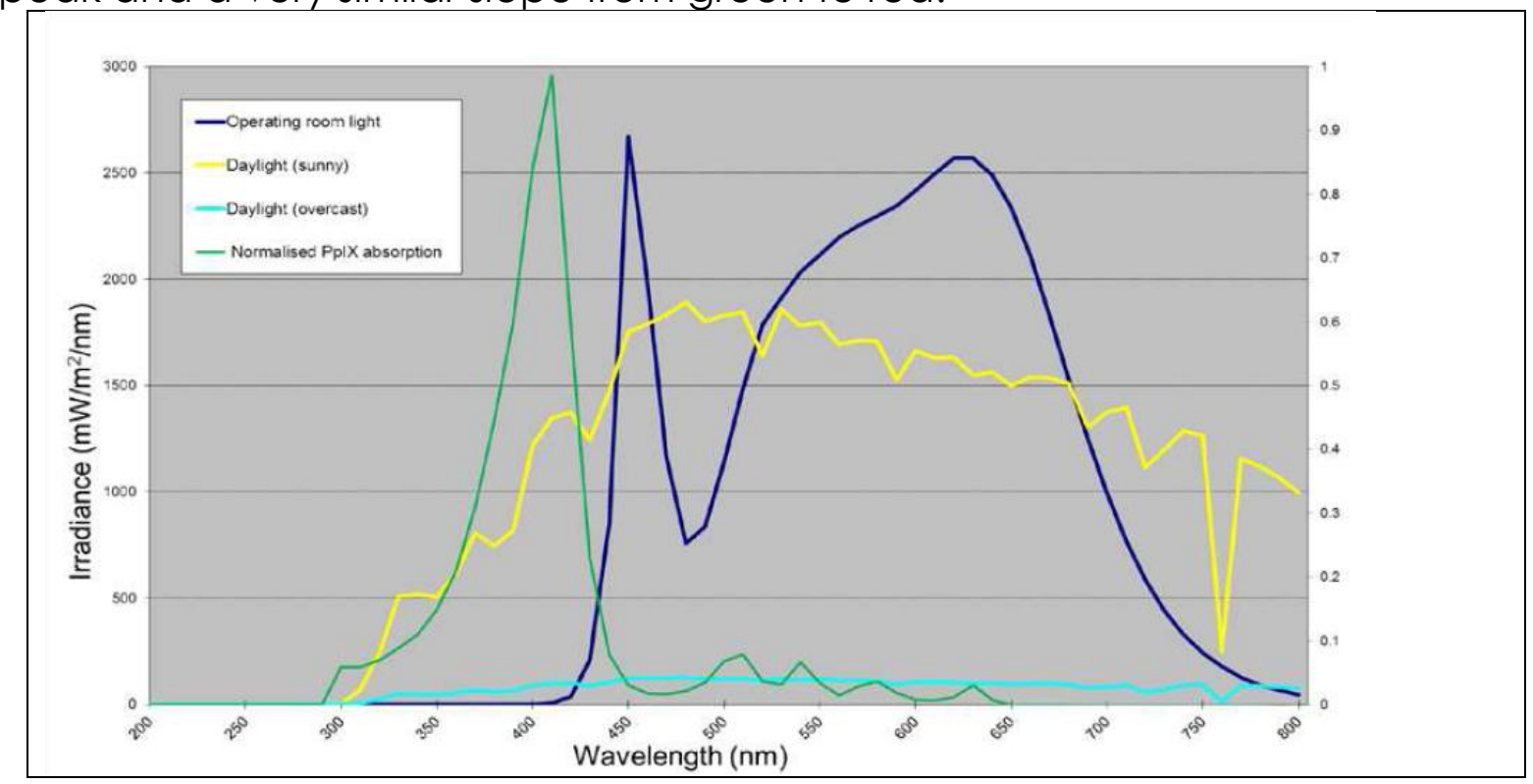


Figure 2 : Light spectra of daylight and operating room light vs normalized PplX absorption spectrum. The daylight irradiance on a clear sunny day can be over ten times that of an overcast day. The artificial white light emission spectrum is similar to that of a clear sunny day particularly between 450 and $650 \mathrm{~nm}$.

However this surgical theater light is developed for surgery and consequently the light is focused at the center. The output of the light falls off radially, limiting the maximum treatment area to $100 \mathrm{~cm}^{2}$ (see Figure 3)

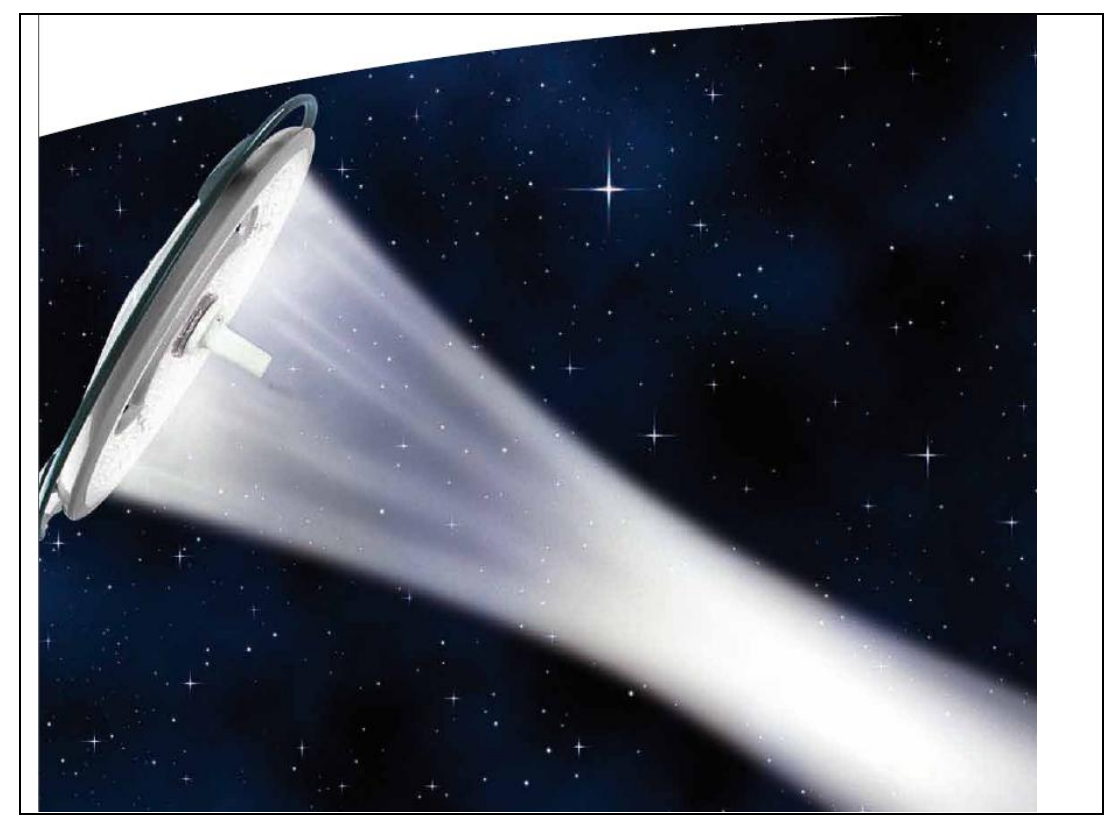

Figure 3: Light distribution of this surgical theater light. The output of the light falls off radially. Optimal parameters are obtained on a $100 \mathrm{~cm}^{2}$ surface only.

With this surgical theater light, the prescribed dose of $50 \mathrm{~J} / \mathrm{cm}^{2}$ in the red waveband was delivered in a treatment time of 120 minutes. The non-uniform distribution of irradiance from the operating room light resulted in dose variation over the treatment area between $50 \mathrm{~J} / \mathrm{cm}^{2}$ at the edge to 125 $\mathrm{J} / \mathrm{cm}^{2}$ at the center of the treatment area. The irradiance in the red waveband ranged from 6.9 to $17.4 \mathrm{~mW} / \mathrm{cm}^{2}$. With these parameters, the mean (SD) effective daylight dose (weighted daylight dose by PpIX activation spectrum) was $21.38(13.25) \mathrm{J} / \mathrm{cm}^{2}$.The minimum daylight dose was $3.20 \mathrm{~J} / \mathrm{cm}^{2}$ and the maximum was $43.00 \mathrm{~J} / \mathrm{cm}^{2}$. Photodynamic therapy using this operating light source was as effective and well-tolerated as daylight photodynamic therapy. Besides, several patients were unable to tolerate CPDT while they reported that they would be happy to undergo either SDLPDT again.

Several companies now proposed devices specially developed to simulate daylight. These devices use white LEDs, they were designed to treat large areas. In 2017, 2 systems are commercialized. 


\section{Medisun}

Medisun daylight 9000 is developed by the company Schulze \& Böhm in Germany. Medisun daylight 9000 contains a three-dimensional irradiation field around the head. Medisun daylight 9000 requires little space $(1.25 \mathrm{~m} \times 1.25 \mathrm{~m})$ and can easily be installed in any room. The affected skin parts can optionally be treated in one or more sessions by individually selecting the 8 LED spotlights. Medisun daylight 9000 can be programmed with different colors and irradiance. The spectral range is adjustable from $400 \mathrm{~nm}$ to $750 \mathrm{~nm}$ and the irradiance is adjustable from 0 to $25 \mathrm{~mW} / \mathrm{cm}^{2}$. An electronic microcontroller allows a dosage input in $\mathrm{J} / \mathrm{cm}^{2}$ and guarantees an exact, automatically calculated exposure time in minutes and seconds. Medisun is currently conducting some scientific studies with this system and data are now available yet.

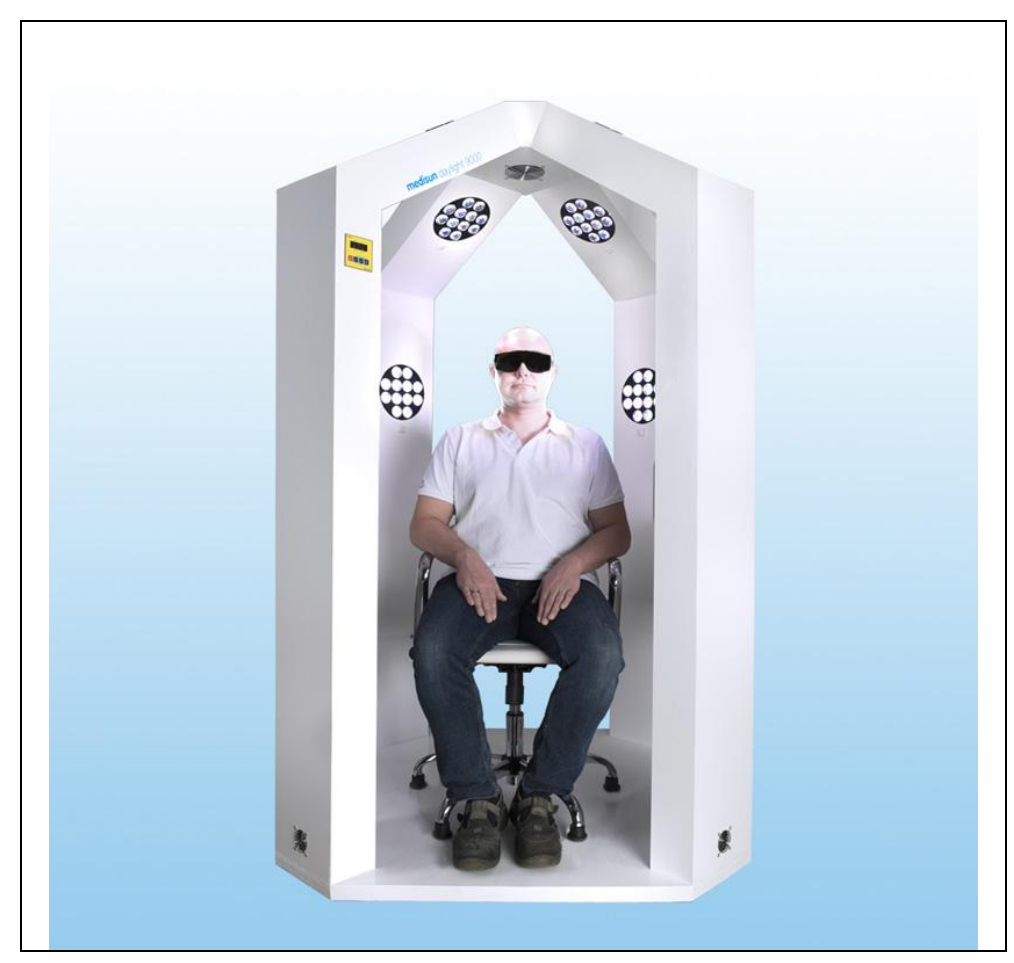


Figure 4: Medisun daylight 9000 (http://medisun.de/de/produkteprofibereich/photodynamische-therapie/medisun-daylight-9000.html)

\section{Dermaris}

Dermaris was developed by the company Surgiris in France (Figure 5). This system used white LEDs. Its spectrum showed a broad waveband in the visible range with high amplitude at $630 \mathrm{~nm}$ (Figure 6). This system was specifically designed for PDT of AK. Consequently the treatment area is much larger than the system evaluated by O'Gorman et al. $320 \mathrm{~cm}^{2}$ versus $100 \mathrm{~cm}^{2}$ for a surgical theater light (Figure 7). 


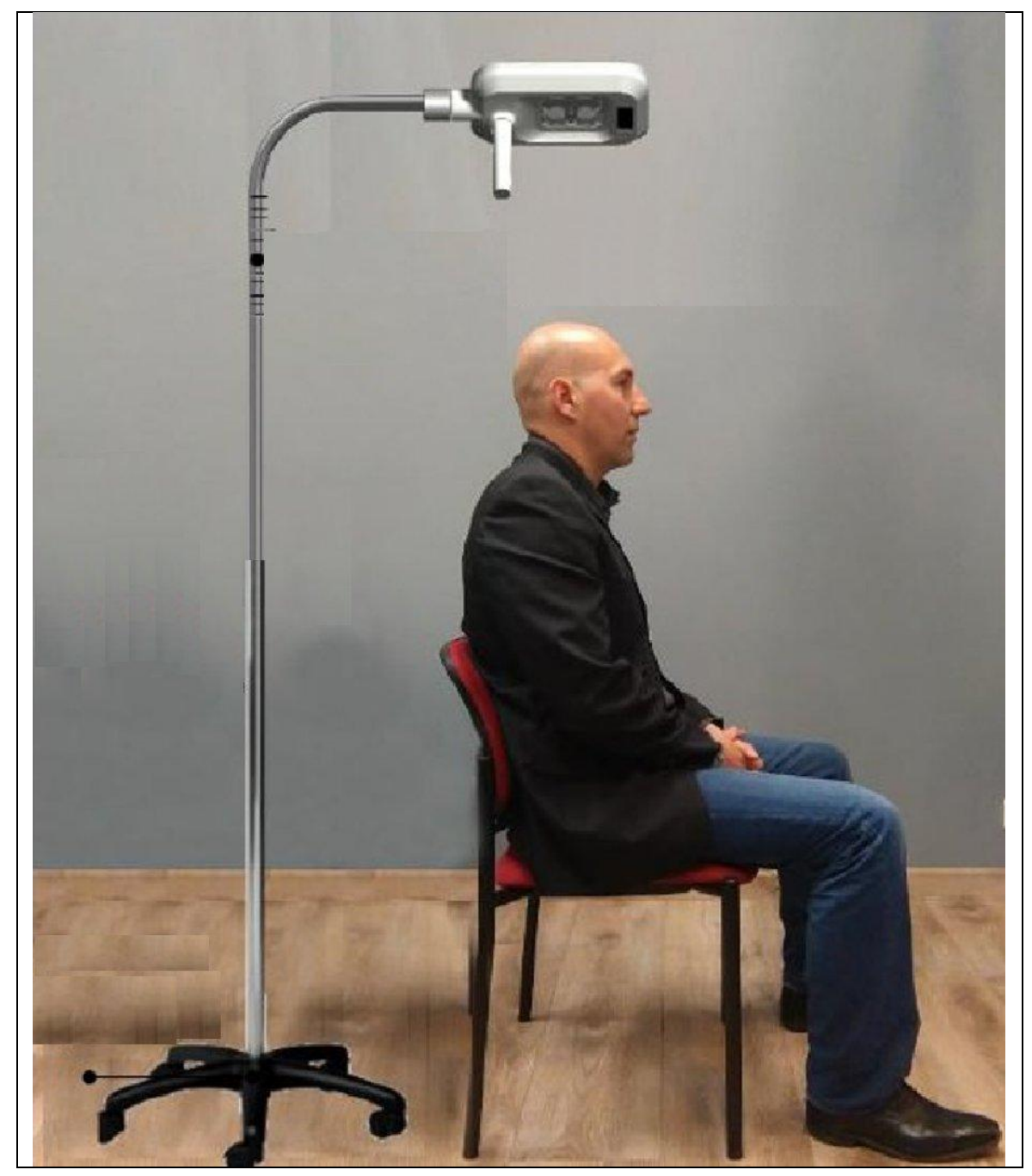

Figure 5: Dermaris system developed by Surgiris

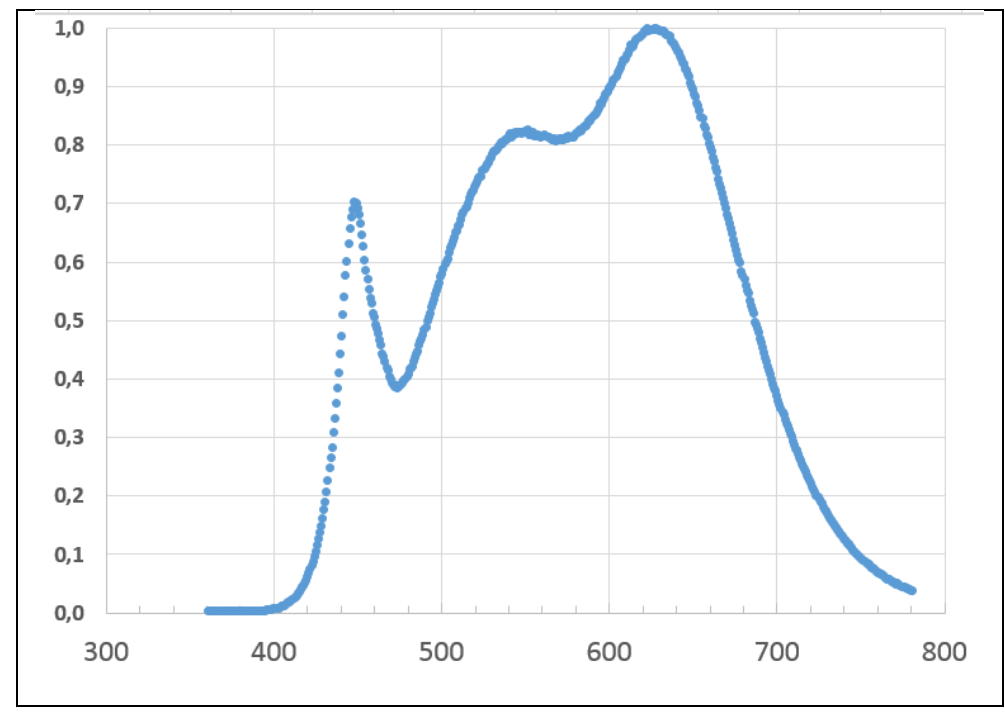

Figure 6: Spectrum of Dermaris. A broad waveband in the visible range with high amplitude at $630 \mathrm{~nm}$ is observed. 


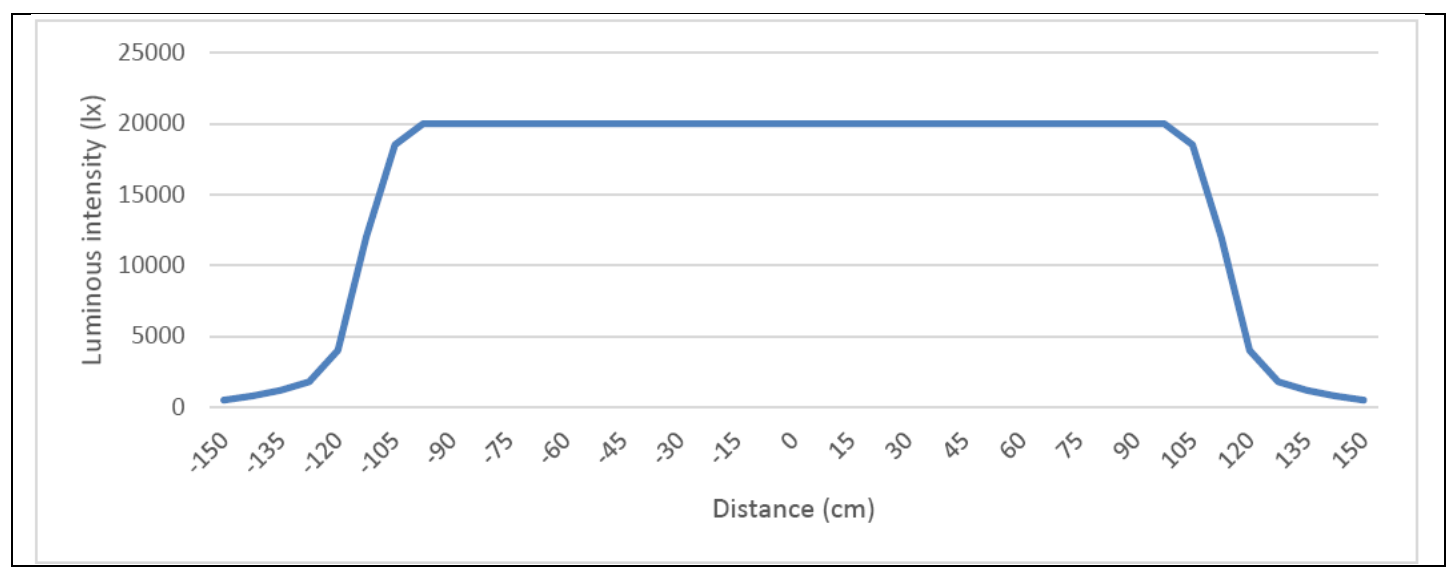

Figure 7: Profile of Dermaris. Thanks to a specific design, the treatment area reaches $320 \mathrm{~cm}^{2}$

\section{IndoorLux ${ }^{\odot}$}

With IndoorLux ${ }^{\circ}$, SWISS RED AG has developed a fresh new concept in stimulated daylight PDT (SDL-PDT). At a distance of 110-150 cm from the light source, the system produces 15,000-25,000 Lux. The lamps mimic the green and red components of daylight. The treatment takes place in a specially equipped PDT room in the dermatologist's practice under the supervision of the practice staff and the treating dermatologist21 (Figure 8). It consists of paired illumination sources installed at the ceiling of the treatment room. Each pair illuminates one patient. Several lamp pairs are combined to illuminate groups of patients simultaneously.

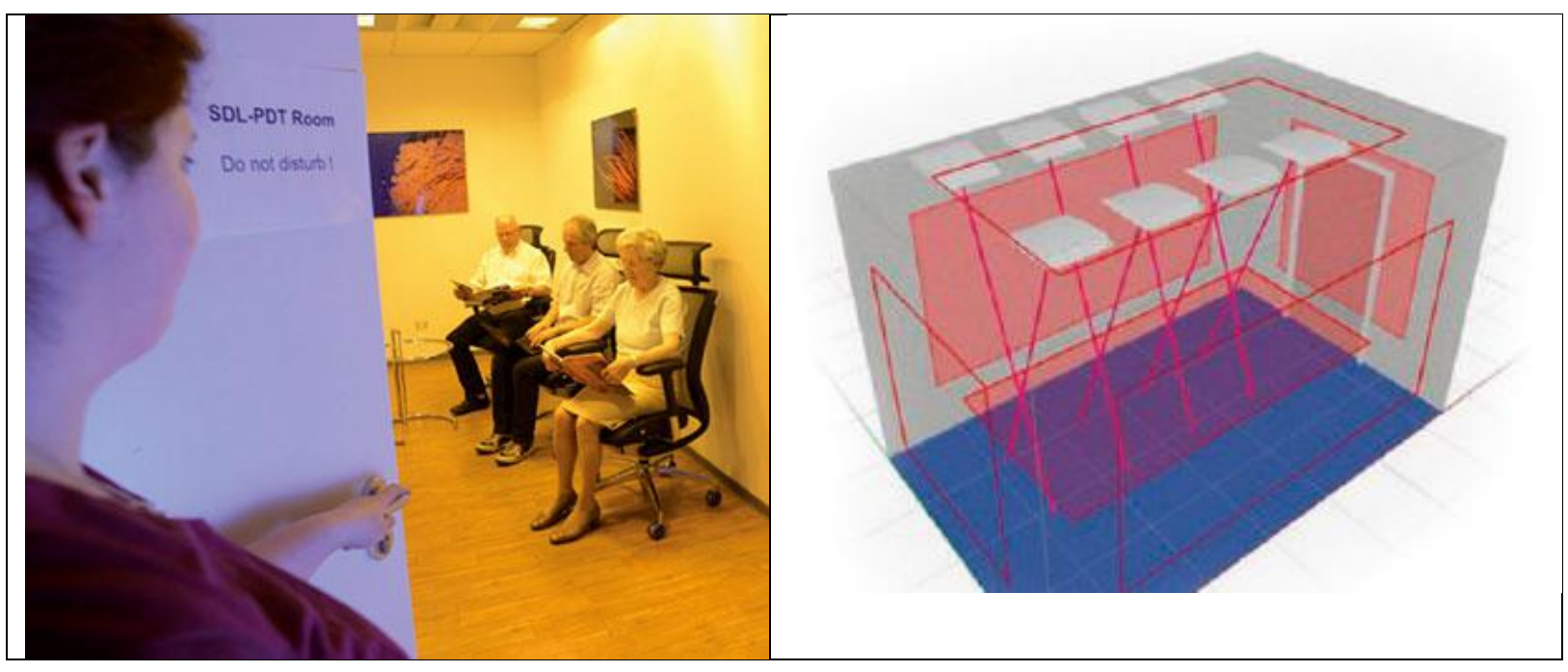

Figure 8: SDL-PDT room equiped with this IndoorLux system. Illumination sources are installed at the ceiling of the treatment room. 


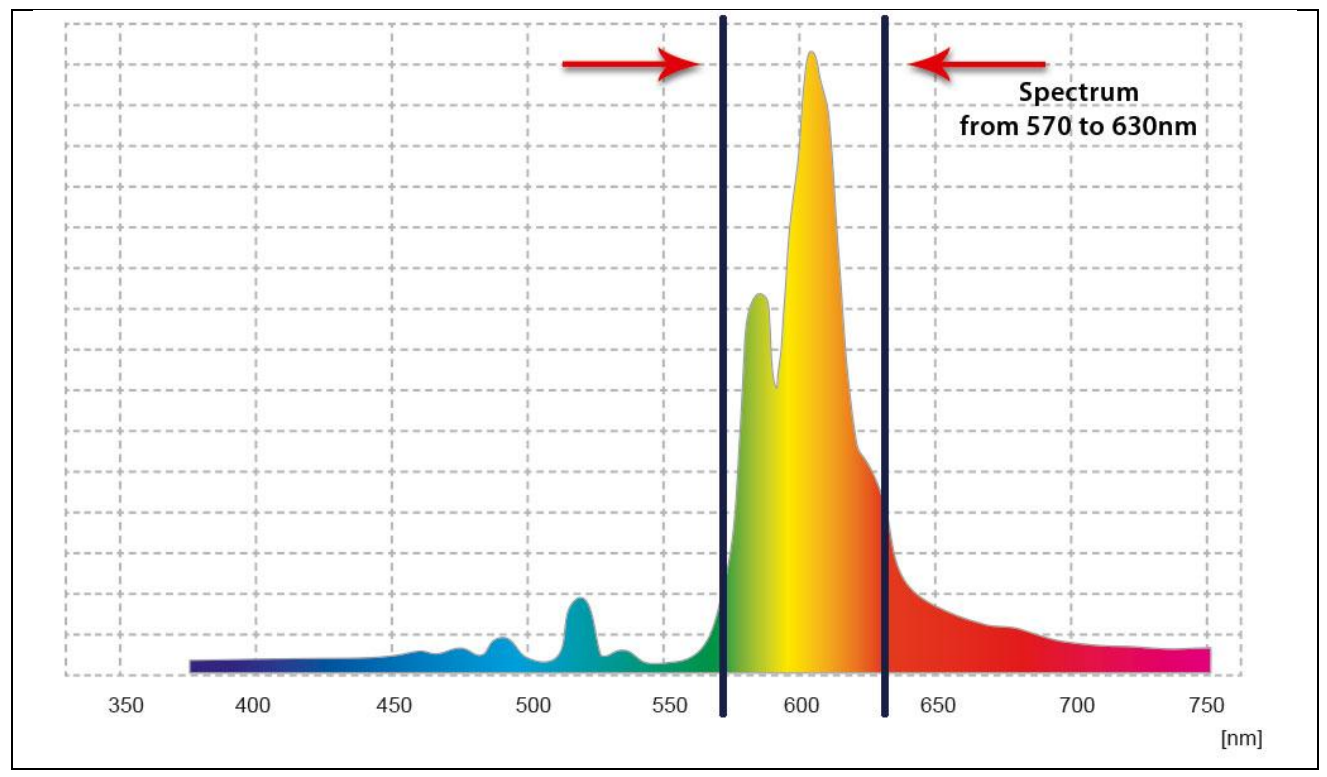

Figure 9 : Spectrum of Indoorlux. Light is mostly emitted between $570 \mathrm{~nm}$ and $630 \mathrm{~nm}$.

At a distance of $110 \mathrm{~cm}$ from the ceiling, the irradiance at $570-590 \mathrm{~nm}$ is 21.14 $\mathrm{mW} / \mathrm{cm}^{2}$ and is $3.04 \mathrm{~mW} / \mathrm{cm}^{2}$ at $620-640 \mathrm{~nm}$ leading to $14.3-24.2 \mathrm{~J} / \mathrm{cm}^{2}$, depending upon the distance from the light source. A retrospective clinical study involving 32 patients with AK performed by Keller et al observed a complete lesion clearance rate in $93 \%{ }^{21}$. This system was well tolerated with no or very mild pain, comparable with NDL-PDT

\section{Conclusion}

Natural DayLight-mediated PhotoDynamic Therapy (NDL-PDT) is an efficacious treatment option for thin actinic keratosis that offers advantages over conventional PDT in terms of tolerability, treatment duration, and cost. However, NDL-PDT cannot be performed in locations with variable or extreme weather conditions, or when temperature is too cold. Thanks to recent developments, Indoor lightning (or simulated daylight: SDL-PDT or Artificial White Light: $A W L$ ) could offer an interesting alternative to NDL-PDT and should be now considered in the armamentarium of dermatologists to fight against precancerous AKs and field cancerization particularly in the elderly population.

\section{References}


1. Wiegell SR, Haedersdal M, Philipsen PA, Eriksen P, Enk CD, Wulf HC. Continuous activation of PplX by daylight is as effective as and less painful than conventional photodynamic therapy for actinic keratoses; a randomized, controlled, single-blinded study. $\mathrm{Br} J$ Dermatol. 2008 Apr;158(4):740-6.

2. O'Mahoney $P$, Khazova M, Higlett M, Lister T, Ibbotson S, Eadie E. Use of illuminance as a guide to effective light delivery during daylight photodynamic therapy in the U.K. Br J Dermatol. 2017 Jun;176(6):16071616.

3. Mordon S. A commentary on the role of skin temperature on the effectiveness of ALA-PDT in Dermatology. Photodiagnosis Photodyn Ther. 2014 Sep; 11 (3):416-9

4. https://en.wikipedia.org/wiki/Daylight

5. Ibbotson S, Stones R, Bowling J, Campbell S, Kownacki S, Sivaramakrishnan M, Valentine R, Morton CA. A consensus on the use of daylight photodynamic therapy in the UK. J Dermatolog Treat. 2017 Jun;28(4):360-367.

6. Cordey H, Valentine R, Lesar A, Moseley H, Eadie E, Ibbotson S. Daylight photodynamic therapy in Scotland. Scott Med J. 2017 Jan 1:36933017695156.

7. Gilaberte Y, Aguilar M, Almagro M, Correia O, Guillén C, Harto A, PérezGarcía B, Pérez-Pérez L, Redondo P, Sánchez-Carpintero I, Serra-Guillén C, Valladares LM. Spanish-Portuguese consensus statement on use of daylight-mediated photodynamic therapy with methyl aminolevulinate in the treatment of actinic keratosis. Actas Dermosifiliogr. 2015 Oct; 106(8):623-31

8. Braathen LR. Daylight photodynamic therapy in private practice in Switzerland: gain without pain. Acta Derm Venereol. 2012 Nov;92(6):652-3

9. Fai D, Romano I, Fai C, Cassano N, Vena GA. Daylight photodynamic therapy with methyl aminolaevulinate in patients with actinic keratoses: a preliminary experience in Southern Italy. G Ital Dermatol Venereol. 2016 pr;151 (2):154-9

10. See JA, Shumack S, Murrell DF, Rubel DM, Fernández-Peñas P, Salmon R, Hewitt D, Foley $P$, Spelman L. Consensus recommendations on the use of daylight photodynamic therapy with methyl aminolevulinate cream for actinic keratoses in Australia. Australas J Dermatol. 2016 Aug:57(3):167-74.

11. Grinblat B, Galimberti G, Pantoja G, Sanclemente G, Lopez M, Alcala D, Torezan L, Kerob D, Pascual T, Chovela E. Feasibility of daylightmediated photodynamic therapy for actinic keratosis throughout the year in Central and South America: a meteorological study. Int J Dermatol. 2016 Sep;55(9):e488-93.

12. Grinblat B, Galimberti G, Chovela E, Sanclemente G, Lopez M, Alcala D, Torezan L, Pantoja G. Daylight-mediated photodynamic therapy for actinic damage in Latin America: consensus recommendations. Photodermatol Photoimmunol Photomed. 2016 Mar;32(2):81- 
13.Lane KL, Hovenic W, Ball K, Zachary CB. Daylight photodynamic therapy: the Southern California experience. Lasers Surg Med. 2015 Feb; $47(2): 168-72$

14. Fitzmaurice S, Eisen DB. Daylight Photodynamic Therapy: What is Known and What is Yet to be Determined. Dermatol Surg. 2016 Mar;42(3):28695.

15. O'Mahoney P, Khazova M, Higlett M, Lister T, Ibbotson S, Eadie E. Use of illuminance as a guide to effective light delivery during daylight photodynamic therapy in the U.K. Br J Dermatol. 2017 Jun;176(6):16071616.

16. Mordon S. A commentary on the role of skin temperature on the effectiveness of ALA-PDT in Dermatology. Photodiagnosis Photodyn Ther. 2014 Sep; 11 (3):416-9.

17. Juzeniene A, Juzenas $P$, Kaalhus $O$, Iani $V$, Moan J. Temperature effect on accumulation of protoporphyrin IX after topical application of 5aminolevulinic acid and its methylester and hexylester derivatives in normal mouse skin. Photochem Photobiol. 2002 Oct;76(4):452-6

18. Lerche CM, Heerfordt IM, Heydenreich J, Wulf HC. Alternatives to Outdoor Daylight Illumination for Photodynamic Therapy--Use of Greenhouses and Artificial Light Sources. Int J Mol Sci. 2016 Feb 29;17(3):309

19. O'Gorman SM, Clowry J, Manley M, McCavana J, Gray L, Kavanagh A, Lally A, Collins P. Artificial White Light vs Daylight Photodynamic Therapy for Actinic Keratoses: A Randomized Clinical Trial. JAMA Dermatol. 2016 Jun 1;152(6):638-44.

20. Manley M., McCavana J., O'Gorman S., Gray L., Kavanagh A., Collins P. Artificial white light photodynamic therapy of actinic keratosis: Commissioning and dosimetry. Physica Medica 32 (2016) 423

21.Kellner, S . Bauriedl, S . Hollstein, U. Reinhold, Simulated-daylight photodynamic therapy with BF-200 aminolaevulinic acid for actinic keratosis: assessment of the efficacy and tolerability in a retrospective study. British Journal of Dermatology (2015) 172, pp 1132-1164 